\title{
Design of a miniaturized UWB MIMO Vivaldi antenna with dual band- rejected performance
}

\author{
Deng-Hui Li ${ }^{1 \text {, a) }}$, Fu-Shun Zhang ${ }^{1}$, Guo-Jun Xie ${ }^{1}$, Hongyin Zhang ${ }^{2}$, and Yi Zhao ${ }^{1}$
}

Abstract A miniaturized ultra-wideband (UWB) multiple-input multipleoutput (MIMO) Vivaldi antenna with dual band-rejected performance is introduced and fabricated in this letter. The method of loading absorption resistors on the ground is used to realize miniaturization. In order to improve the isolation between the two ports, a T-slot is etched between two Vivaldi elements. At last, by etching the split ring resonator (SRR) slits on the ground, and placing two split ring resonators (SRRs) near the feed balun structures, the dual band-rejected characteristics are achieved. Then the designed antenna prototype is fabricated and measured, and the measured results show that the operating frequency of the proposed antenna is $2.5-12.0 \mathrm{GHz}$, and the dual-rejected bands are $5.1-5.9 \mathrm{GHz}$ and $6.6-7.1$ $\mathrm{GHz}$ respectively, and the isolation between the two ports is more than 15 $\mathrm{dB}$ over the UWB range (3.1-10.6 GHz), the size of the designed antenna is only $26 \times 24.5 \times 0.6 \mathrm{~mm}^{3}$.

Keywords: miniaturization, MIMIO Vivaldi antenna, T-slot, dual bandrejected

Classification: Microwave and millimeter-wave devices, circuits, and modules

\section{Introduction}

Ultra-wideband (UWB) technologies are widely used because of some outstanding characteristics just like high immunity to multipath interference, high-resolution capability, low cost, and high-data-rate transmission [1]. Nevertheless, multipath fading and channel fading will bring about instability of UWB technology [2]. Multiple-input multiple-output (MIMO) technology, which plays a key role in the UWB systems, can increase the communication quality obviously without extra bandwidth or increasing transmit power [3, 4, 5].

It is well known that MIMO antenna for UWB applications requires compact size and low mutual coupling. However, the mutual coupling will increase significantly if the size of the MIMO antenna is reduced. Hence, many different structures have been carried out to reduce the mutual coupling of MIMO antennas. Low mutual coupling could be accomplished by placing an isolating metal strip between the two radiating elements [6, 7], and symmetrical placements $[8,9,10]$, placing perpendicularly or orthogonally $[11,12,13,14]$, etching different kinds of slots on the

\footnotetext{
${ }^{1}$ National Key Laboratory of Antennas and Microwave Technology, Xidian University, Xi'an 710071, China

2 Nanjing Research Institute of Electronics Technology, Guorui Road No.8, Yuhuatai District, Nanjing, China

a)dhui_li@163.com
}

ground $[15,16,17,18]$, introducing a fence-type decoupling structure at the ground [19], using parasitic element between the antenna ports [20], etching complementary split ring resonator (CSRR) on the ground or loading SRR [21, 22]. These effective methods mentioned above can improve the isolation obviously.

However, the UWB range from 3.1 to $10.6 \mathrm{GHz}$ would bring about interference to the existing narrowband communication systems just like WLAN $(5.15-5.85 \mathrm{GHz})$ and $\mathrm{X}$-band communication satellites $(7.9-8.4 \mathrm{GHz})$, so it is necessary to design the band-rejected structures to decrease the interference. To deal with this problem, some antennas with band-rejected function have been discussed. In [23, 24, 25], different-shaped $1 / 4 \lambda$ open slots are etched into the radiator to obtain the rejected band. By introducing two split ring resonator (SRR) slits on the ground, the band-rejected function is obtained in [26]. In [27], by forming a G-shaped structure on the element, the rejected band at $5.5 \mathrm{GHz}$ is achieved. And two strips are added between the elements to create a band-notched function at $5.5 \mathrm{GHz}$ in [28].

In this letter, a UWB MIMO Vivaldi antenna with dual band-rejected performance is introduced. The target size of the antenna is $26 \times 24.5 \times 0.6 \mathrm{~mm}^{3}$ which is designed on the F4BM-2 substrate, and the isolation between two ports could be obviously improved after etching a T-slot on the ground. By employing SRR slits on the ground, the band from 6.6-7.1 GHz could be rejected. Meanwhile, two SRRs are added close to the microstrip-slot balun structures to reject the 5.1-5.9 GHz band. And the band-rejected theory is analyzed in the following content.

\section{Antenna structure and design analysis}

\subsection{Antenna structure}

According to Fig. 1, the structure of the miniaturized MIMO Vivaldi antenna with dual band-rejected performance has two identical symmetrical Vivaldi elements which are fed by two symmetrical microstrip-slot balun structures. It is fabricated on a $26 \times 24.5 \mathrm{~mm}^{2}$ F4BM- 2 substrate with a relative permittivity of 2.65 , thickness of $0.6 \mathrm{~mm}$. To achieve miniaturization, four resistors are loaded on the ground. Meanwhile, to increase the isolation between two Vivaldi elements, a T-slot is introduced on the ground. Furthermore, a pair of SRRs are introduced to generate the rejected band at WLAN (5.15-5.85 GHz). And two SRR slits are embedded in the ground to achieve the rejection of IEEE INSAT/Super-Extended C band (6.7-7.1 GHz). The opti- 
mized design parameters of the antenna are shown in Table I. And the tapered curve function of the Vivaldi antenna is depicted as follows [29]:

$$
y= \pm\left(c_{1} e^{\alpha z}+c_{2}\right)
$$

Where $c_{1}$ and $c_{2}$ are decided by $\alpha$ and the position of two points $\mathrm{p}_{1}\left(\mathrm{y}_{1}, \mathrm{z}_{1}\right)$ and $\mathrm{p}_{2}\left(\mathrm{y}_{2}, \mathrm{z}_{2}\right)$

$$
\begin{gathered}
c_{1}=\frac{y_{2}-y_{1}}{e^{\alpha z_{2}}-e^{\alpha z_{1}}} \\
c_{2}=\frac{y_{1} e^{\alpha z_{2}}-y_{2} e^{\alpha z_{1}}}{e^{\alpha z_{2}}-e^{\alpha z_{1}}}
\end{gathered}
$$

Where $\mathrm{p}_{1}\left(\mathrm{y}_{1}, \mathrm{z}_{1}\right)$ and $\mathrm{p}_{2}\left(\mathrm{y}_{2}, \mathrm{z}_{2}\right)$ are respectively the starting and ending coordinate values of the exponential curve in Fig. 1 (a), and both $c_{1}$ and $c_{2}$ are constants.

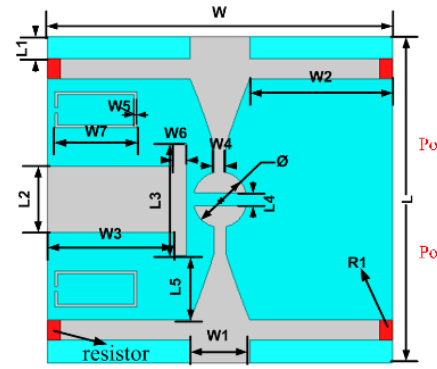

(a)

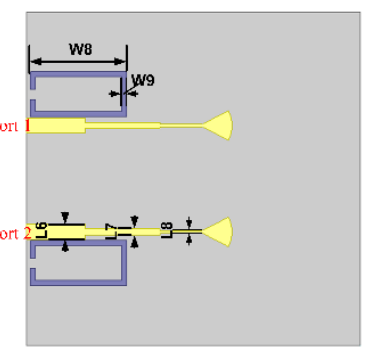

(b)
Fig. 1 Structure of the UWB MIMO Vivaldi antenna. (a) Front view. (b) Back view.

Table I The optimized design parameters of the antenna

\begin{tabular}{|c|c|c|c|c|c|c|c|}
\hline Parameters & W & W1 & W2 & W3 & W4 & W5 & W6 \\
\hline Value/mm & 26 & 4.5 & 10.75 & 9.5 & 0.7 & 0.2 & 1 \\
\hline Parameters & W7 & W8 & W9 & L & L1 & L2 & L3 \\
\hline Value/mm & 5.8 & 6.7 & 0.4 & 26 & 1.65 & 5.0 & 8.5 \\
\hline Parameters & L4 & L5 & L6 & L7 & L8 & $\Phi$ & \\
\hline Value/mm & 1 & 5 & 1.2 & 0.5 & 0.2 & 2 & \\
\hline
\end{tabular}

\subsection{Design of miniaturized Vivaldi element}

The traditional Vivaldi structure is shown in Fig. 2 (a), but the simulated $\left|\mathrm{S}_{11}\right|$ is just from 3.9 to $12.0 \mathrm{GHz}$ as seen in Fig. 3, which cannot meet the requirement of the whole UWB range. To achieve miniaturization, two resistors are loaded on the ground which can absorb the excess current in the low-frequency band, and the improved Vivaldi element is as shown in Fig. 2 (b).

With the reference to Fig. 3, the comparison of simulated $\left|S_{11}\right|$ of the two different elements is shown. After the improvement, it is observed that the minimum working frequency of the Vivaldi element is lowered. So after loading the resistors, the simulated $\left|\mathrm{S}_{11}\right|<-10 \mathrm{~dB}$ of improved element II is from 2.5 to $12.0 \mathrm{GHz}$, meeting the requirement of the UWB range.

\subsection{Design of the Vivaldi MIMO antenna}

With the reference to Fig. 4 (a), two identical miniaturized Vivaldi elements are simply combined together. As can

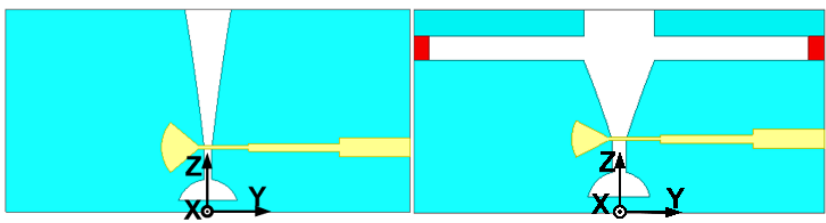

(a)

(b)

Fig. 2 The evolution of the Vivaldi element structures. (a) Element I. (b) Element II.

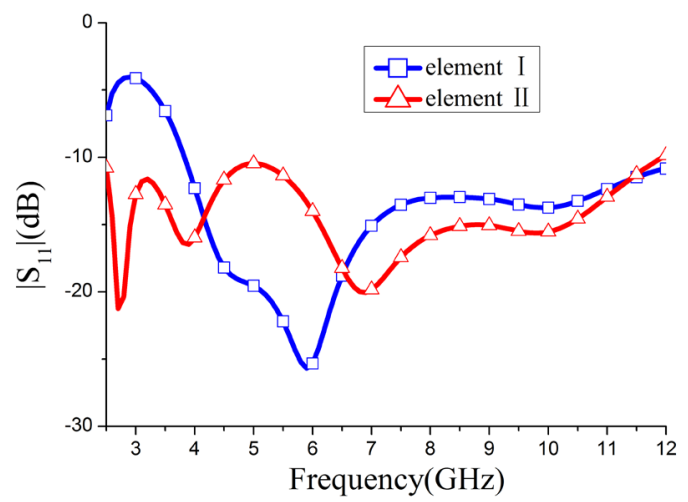

Fig. 3 Comparison of simulated $\left|\mathrm{S}_{11}\right|$ of the two elements.

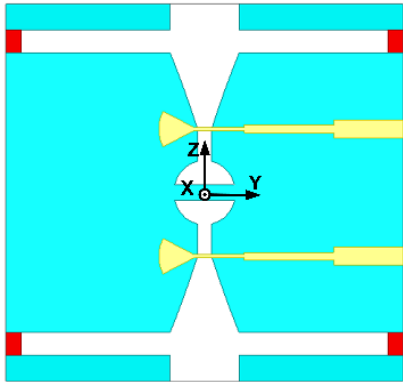

(a)

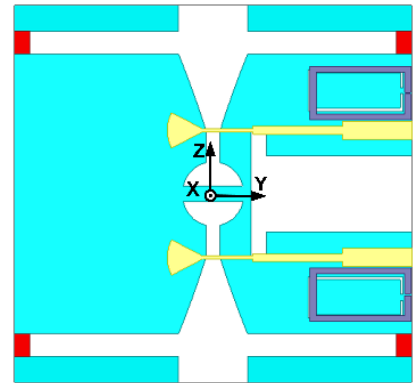

(b)
Fig. 4 The evolution of the MIMO Vivaldi antenna. (a) Antenna I. (b) Antenna II.

be seen, the size of the combined Vivaldi MIMO antenna is very small, so the mutual coupling between the two ports will be higher due to the very short distance and the existence of surface currents on the ground. As is analyzed above, we should make an improvement to lengthen the distance between the two elements, then the T-slot is introduced to lengthen the current distance between the elements to obtain better isolation as is seen in Fig. 4 (b).

Fig. 5 (a) plots the simulated $\left|S_{12}\right|$ of the two different structures. It is distinctly observed that before etching the Tslot, the isolation between the Vivaldi elements is very poor during 3-5 GHz. After the improvement, the $\left|S_{12}\right|$ of the Antenna II decreases significantly from 3 to $5 \mathrm{GHz}$, which indicates the isolation has increased. The reason why the isolation can be improved is because the distance is extended between the two ports.

\subsection{Band-rejected mechanism}

(a) Surface Current Distributions

With the reference to the Fig. 4 (b), the SRRs are added near each microstrip-slot balun to reject WLAN band, and the two SRR slits which are etched on the ground to reject the 


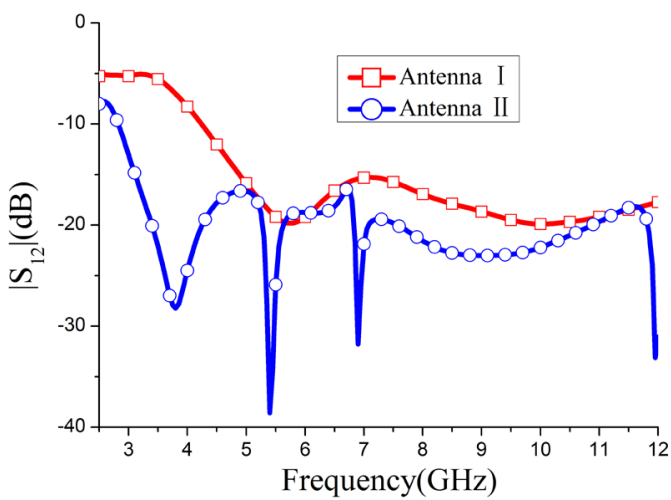

(a)

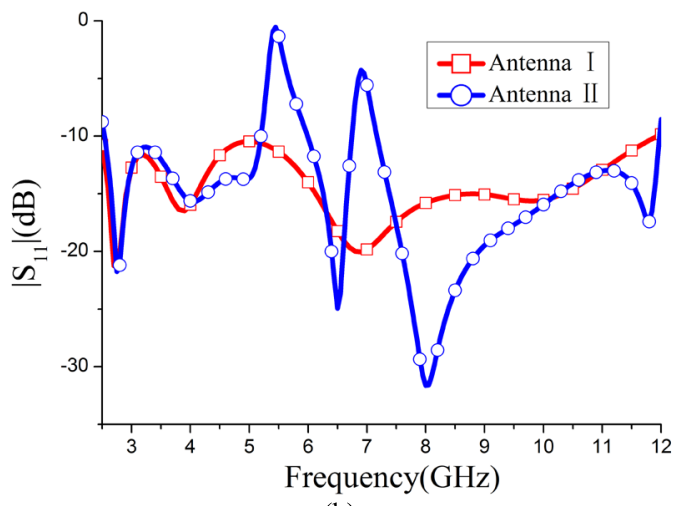

(b)

Fig. 5 S-parameters of the Antenna I and Antenna II. (a) $\left|S_{12}\right|$. (b) $\left|S_{11}\right|$.

IEEE INSAT/Super-Extended C-band. To understand the influence of the etched slits and SRRs in depth, Fig. 6 plots the current distribution when the operating frequency is at 5.5 and $7.0 \mathrm{GHz}$, respectively.

When operating frequency is at $5.5 \mathrm{GHz}$, with the reference to Fig. 6 (a), the SRR can be seen as a resonator which can generate a resonance result. There is a large quantity of current energy gathering on the SRR, which impairs the radiation ability of the antenna. When operating frequency is at $7.0 \mathrm{GHz}$, with the reference to Fig. 6 (b), it is obvious that the current on the two sides of the slit are in the opposite directions, the radiation from both sides will counteract in the far fields. Therefore, the current distributions demonstrate that dual band rejection can be realized. As a result, with the reference to Fig. 5 (b), the impedance bandwidth of the eventually given Antenna II is $2.5-12.0 \mathrm{GHz}$ with two rejected bands $5.1-5.9 \mathrm{GHz}$ and $6.7-7.1 \mathrm{GHz}$.

(b) Parametric Study

The length of the SRR can influence the rejected bands, Fig. 7 (a) shows the different curves of $\left|S_{11}\right|$ when W7 is different, we can easily find that when the value of $\mathrm{W} 7$ increases, the center of the high rejected band decreases and the center of the low rejected band remains the same. When the value of W8 increases, Fig. 7 (b) shows the center of low rejected band decreases with almost unchanged high rejected band. According to the Fig. 7 and above analysis, we can conclude that the dual rejected bands are highly independent of each other, and the length of the SRR can be adjusted appropriately to change the rejected bands.

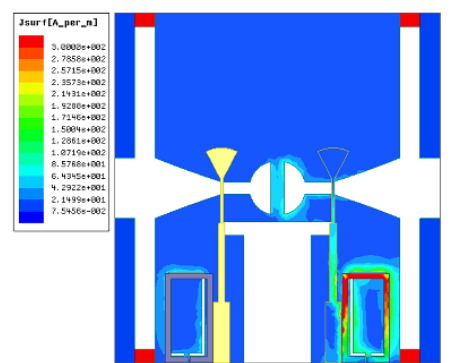

(a)

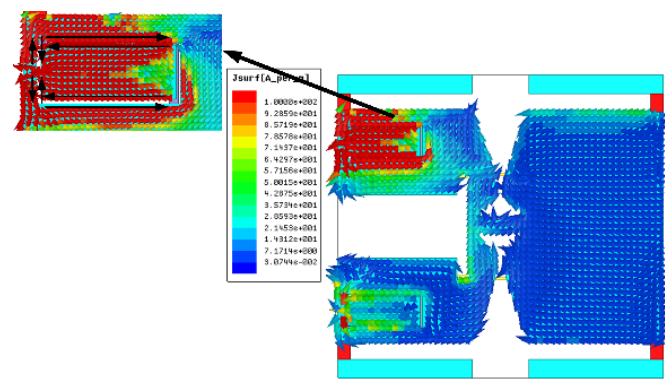

(b)

Fig. 6 Current distributions of Antenna II. (a) $5.5 \mathrm{GHz}$. (b) $7.0 \mathrm{GHz}$.

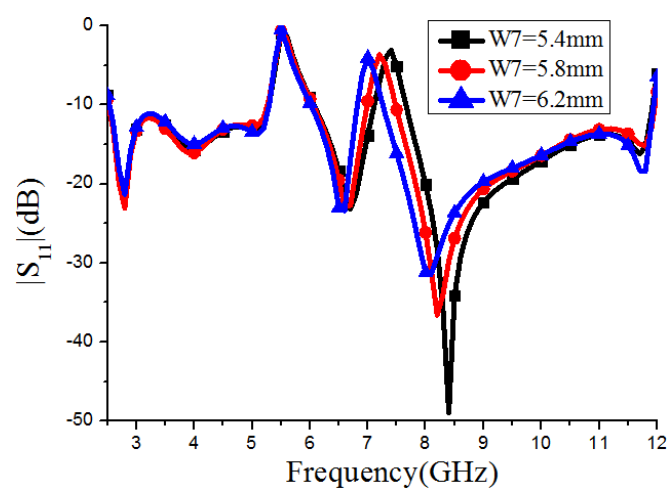

(a)

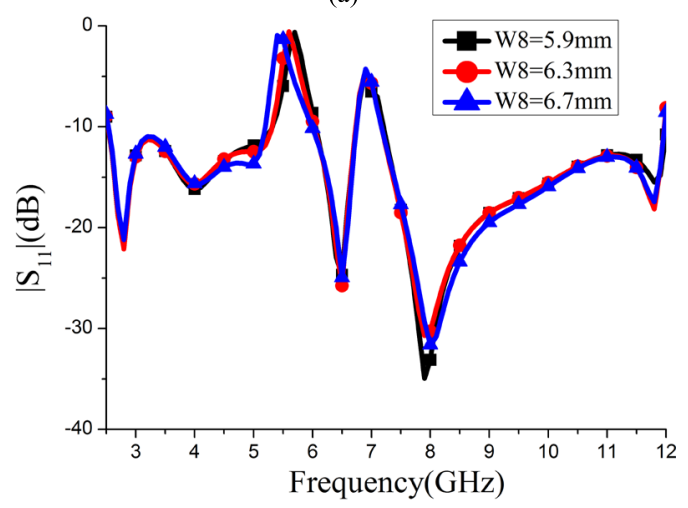

(b)

Fig. 7 The curves of $\left|S_{11}\right|$ with different W7 and W8 (a) W7. (b) W8.

\section{Results of simulate $d$ and measured}

To prove the simulation, a prototype of the UWB MIMO Vivaldi antenna has been finally fabricated, and measured. The photographs of the fabricated antenna are shown in Fig. 8. With the reference to Fig. 9, it can be seen that the results of the measured and simulated S-parameters are in great agreement. The measured $\left|\mathrm{S}_{11}\right|$ is lower than $-10 \mathrm{~dB}$ 


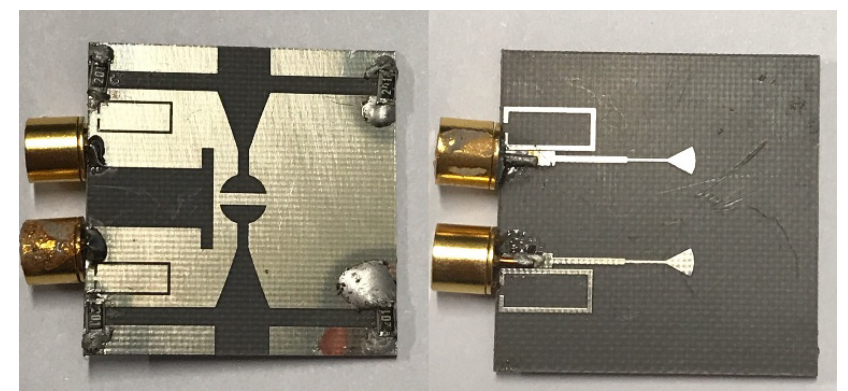

Fig. 8 Fabricated photos of the designed UWB MIMO antenna.

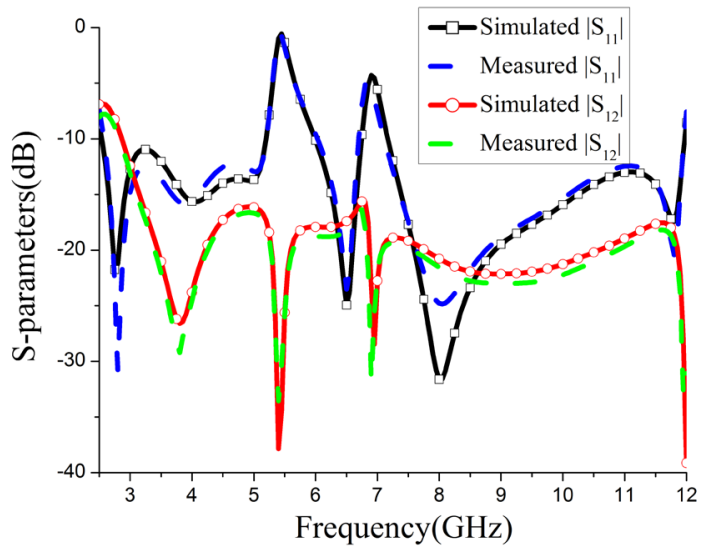

Fig. 9 Simulated and measured S-parameters.

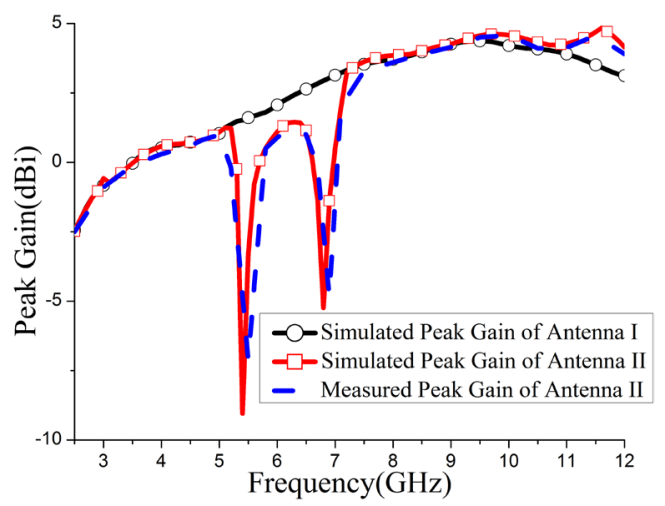

Fig. 10 Measured and simulated peak gain of the Antenna I and II.

from 2.5 to $12.0 \mathrm{GHz}$, covering the whole UWB frequency range. Besides, the measured $\left|S_{12}\right|$ is lower than $-15 \mathrm{~dB}$ throughout the UWB range, representing a good isolation between two ports.

When the port 1 is excited, Fig. 10 plots the peak gain of the proposed Antenna I and II. We can see that the peak gain of the Antenna I is basically stable, and the peak gain of the Antenna II descends distinctly in the dual-rejected bands, and the minimum gain in the dual-rejected bands are -7.1 $\mathrm{dBi}$ and $-4.8 \mathrm{dBi}$ respectively, which show that the designed antenna has achieved good dual band-rejected function. In the meantime, we can find that the gain in the low frequency is lower compared to the traditional Vivaldi antenna, this is because the designed antenna is loaded with absorption resistors, which can absorb the reflected wave in the low frequency and achieve miniaturization, but also result in a loss of gain.

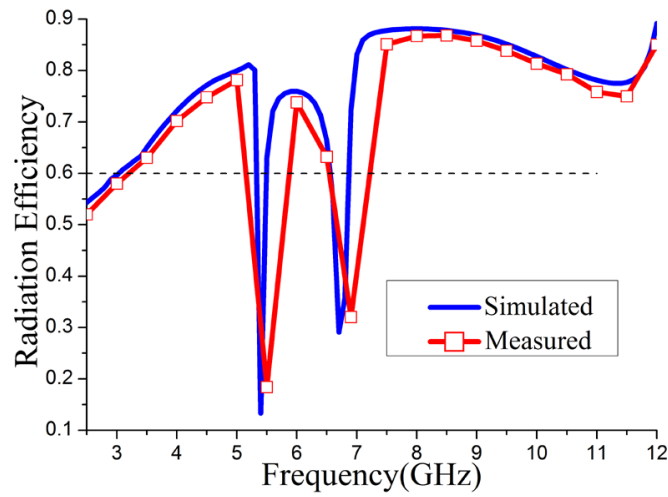

Fig. 11 Measured and simulated radiation efficiency of the designed antenna.

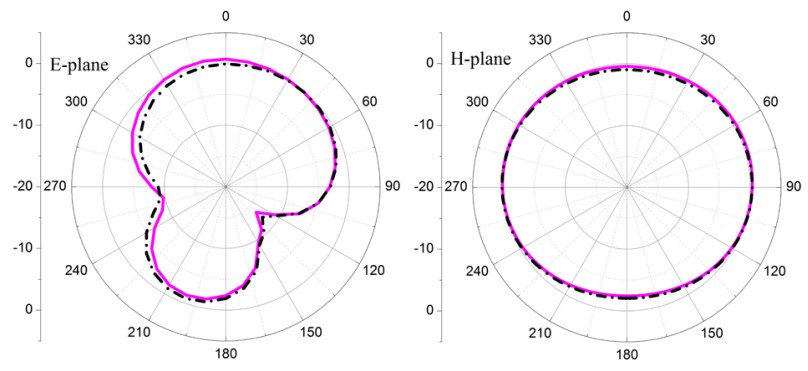

(a)

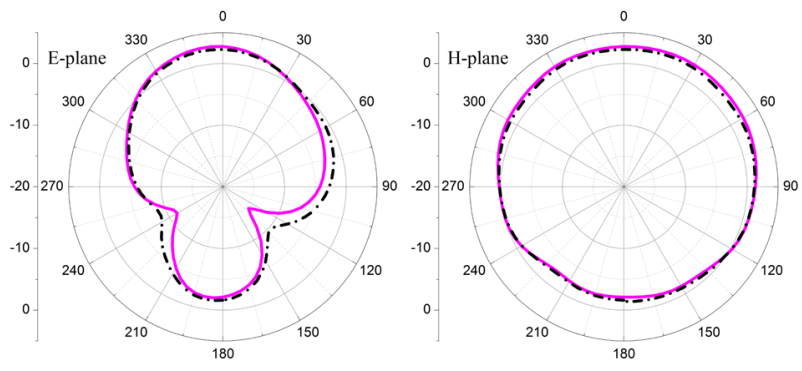

(b)

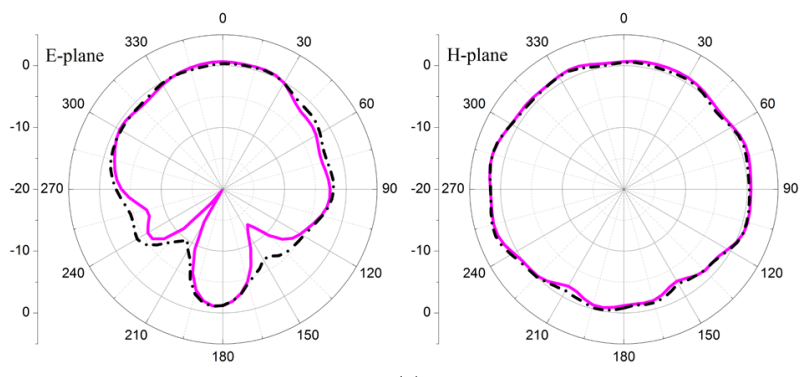

(c)

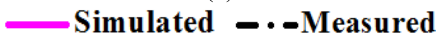

Fig. 12 Measured and simulated radiation patterns of the antenna. (a) Port 1 at $4.5 \mathrm{GHz}$. (b) Port 1 at $7.5 \mathrm{GHz}$. (c) Port 1 at $10.5 \mathrm{GHz}$.

Fig. 11 shows the radiation efficiency of the designed antenna, the radiation efficiency of the antenna is more than $60 \%$ from 3.1 to $10.6 \mathrm{GHz}$ except the dual-rejected bands, and the radiation efficiency descends distinctly from 3.1 to $4 \mathrm{GHz}$, it is because of the adverse effect of absorption resistors.

Fig. 12 illustrates the measured and simulated radiation patterns of the UWB MIMO Vivaldi Antenna at 4.5, 7.5, and $10.5 \mathrm{GHz}$ when the port 1 is fed. It is observed the 


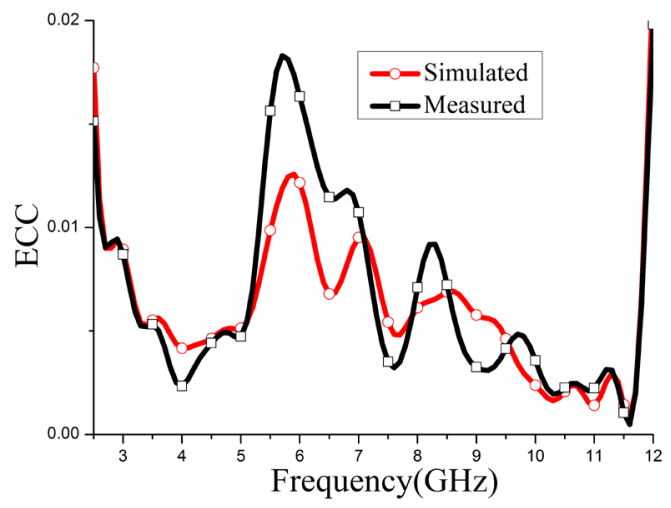

Fig. 13 Measured and simulated radiation patterns of the antenna.

Table II Performance comparisons of the MIMO antennas

\begin{tabular}{|c|c|c|c|c|c|c|}
\hline Ref. & Size $\left(\mathrm{mm}^{2}\right)$ & $\begin{array}{c}\text { Impedance } \\
\text { bandwidth } \\
(\mathrm{GHz})\end{array}$ & $\begin{array}{c}\text { Rejected } \\
\text { bands } \\
(\mathrm{GHz})\end{array}$ & $\begin{array}{c}\text { Isolation } \\
(\mathrm{dB})\end{array}$ & ECC & Efficiency \\
\hline$[11]$ & $32 \times 32$ & $3.1-10.6$ & - & $>15$ & $<0.02$ & $>0.6$ \\
\hline$[12]$ & $38.5 \times 38.5$ & $3.1-11.8$ & $5.03-5.97$ & $>15$ & $<0.02$ & $>0.75$ \\
\hline$[19]$ & $50 \times 35$ & $3.0-11.0$ & - & $>25$ & $<0.004$ & $>0.8$ \\
\hline$[23]$ & $27 \times 30$ & $3.0-11.0$ & $\begin{array}{c}3.3-3.7 \& \\
5.15-5.85\end{array}$ & $>20$ & - & $>0.65$ \\
\hline$[26]$ & $48 \times 48$ & $2.5-12.0$ & $5.1-6$ & $>15$ & $<0.005$ & - \\
\hline$[28]$ & $22 \times 36$ & $3.1-11.0$ & $5.15-5.85$ & $>15$ & $<0.1$ & $>0.7$ \\
\hline Pro. & $26 \times 24.5$ & $2.5-12.0$ & $\begin{array}{c}5.1-5.9 \& \\
6.6-7.1\end{array}$ & $>15$ & $<0.02$ & $>0.6$ \\
\hline
\end{tabular}

UWB MIMO Vivaldi antenna has good radiation with endfire characteristic.

The envelope correlation coefficient (ECC) represents an important parameter to evaluate the diversity performance of the MIMO antenna, which is calculated by the following formula [30]:

$$
E C C=\frac{\left|S_{11}^{*} S_{12}+S_{21}^{*} S_{22}\right|^{2}}{\left(1-\left(\left|S_{11}\right|^{2}+\left|S_{21}\right|^{2}\right)\right)\left(1-\left(\left|S_{22}\right|^{2}+\left|S_{12}\right|^{2}\right)\right)}
$$

With the reference to Fig. 13, the simulated and measured ECC is depicted. And we can see that two curves have the same trend. A very small ECC of less than 0.02 is achieved throughout the total UWB range (3.1-10.6 GHz), demonstrating the proposed MIMO Vivaldi antenna has good diversity characteristics.

Finally the designed UWB MIMO Vivaldi antenna is compared with the similar antennas that have been published, and the key data of these antennas are briefly summarized in Table II.

According to the comparison of the various data of these antennas in Table II, it is observed that the designed UWB MIMO antenna not only has a small size and wide bandwidth, but also has dual band-rejected function. However, due to the negative impact of the absorption resistors, the efficiency of the antenna has decreased to some extent.

\section{Conclusion}

In this letter, a miniaturized dual band-rejected UWB MIMO Vivaldi antenna is proposed, measured and analyzed. Resistors are utilized on the ground to achieve miniaturization, the size of the antenna is $26 \times 24.5 \times 0.6 \mathrm{~mm}^{3}$, and the proposed antenna has an impedance bandwidth from 2.5 to 12.0 GHz. A T-slot is etched between the Vivaldi elements to improve the isolation to above $15 \mathrm{~dB}$ through the UWB band from 3.1 to $10.6 \mathrm{GHz}$. Two SRR slits are introduced on the ground to generate a band rejection from 6.7 to $7.1 \mathrm{GHz}$. And adding two SRRs can achieve the other band rejection from 5.1 to $5.9 \mathrm{GHz}$. The finally simulated and measured results both prove that the designed antenna has not only small size but also good electrical performance, which can be a good candidate for UWB wireless applications.

\section{References}

[1] Z.N. Chen and T.S.P. See: "Antennas for UWB applications," in Antennas for Protable Devices (Wiley, 2007) 231 (DOI: 10.1002/ 9780470319642.ch7).

[2] Y. Zhao, et al.: "A compact dual band-notched MIMO diversity antenna for UWB wireless applications," Prog. Electromagn. Res. C 89 (2019) 161 (DOI: 10.2528/PIERC1811190).

[3] A. Al-Rawi, et al.: "A new compact wideband MIMO antenna-the double-sided tapered self-grounded monopole array," IEEE Trans. Antennas Propag. 62 (2019) 3365 (DOI: 10.1109/ TAP.2014.2309985).

[4] S.-M. Liao, et al:: "Wideband miniaturized 8-element sub-6 GHz MIMO antenna system for mobile handset applications," IEICE Electron. Express 16 (2019) 20190631 (DOI: 10.1587/elex.16.20190631).

[5] H. Li, et al.: "A compact planar MIMO antenna system of four elements with similar radiation characteristics and isolation structure," IEEE Antennas Wireless Propag. Lett. 8 (2009) 1107 (DOI: 10.1109/LAWP.2009.2034110).

[6] T. K. Roshna, et al.: "A compact UWB MIMO antenna with reflector to enhance isolation," IEEE Trans. Antennas Propag. 63 (2009) 1873 (DOI: 10.1109/TAP.2015.2398455).

[7] C.-M. Luo, et al:: "A decoupling method between two tri-band antennas for WLAN/WiMAX applications," IEICE Electron. Express 14 (2017) 20170534 (DOI: 10.1587/elex.14.20170534).

[8] G. Srivastava and A. Mohan: "Compact MIMO slot antenna for UWB applications,” IEEE Antennas Wireless Propag. Lett. 15 (2016) 1057 (DOI: 10.1109/LAWP.2015.2491968).

[9] J.-M. Lee, et al.: "A compact ultrawideband MIMO antenna with WLAN band-rejected operation for mobile devices," IEEE Antennas Wireless Propag. Lett. 11 (2012) 990 (DOI: 10.1109/ LAWP.2012.2214431).

[10] X.-L. Liu, et al.: "A compact ultrawideband MIMO antenna using QSCA for high isolation,” IEEE Antennas Wireless Propag. Lett. 13 (2014) 1497 (DOI: 10.1109/LAWP.2014.2340395).

[11] J. Ren, et al.: "Compact printed MIMO antenna for UWB applications,” IEEE Antennas Wireless Propag. Lett. 13 (2014) 1517 (DOI: 10.1109/LAWP.2014.2343454).

[12] L. Kang, et al.: "Compact offset microstrip-fed MIMO antenna for band-notched UWB applications," IEEE Antennas Wireless Propag. Lett. 14 (2015) 1754 (DOI: 10.1109/LAWP.2015.2422571).

[13] L.Y. Nie, et al.: "Structure-shared planar UWB MIMO antenna with high isolation for mobile platform," IEEE Trans. Antennas Propag. 67 (2019) 2735 (DOI: 10.1109/TAP.2018.2889596).

[14] K. Ding, et al.: "Compact broadband MIMO antenna with parasitic strip,” IEEE Antennas Wireless Propag. Lett. 16 (2019) 2349 (DOI: 10.1109/LAWP.2017.2718035).

[15] J.-Y. Deng, et al.: "An ultrawideband MIMO antenna with a high isolation," IEEE Antennas Wireless Propag. Lett. 15 (2016) 182 (DOI: 10.1109/LAWP.2015.2437713).

[16] Y.-Y. Liu and Z.-H. Tu: "Compact differential band-notched stepped-slot UWB-MIMO antenna with common-mode suppression,” IEEE Antennas Wireless Propag. Lett. 16 (2017) 593 (DOI: 10.1109/LAWP.2016.2592179).

[17] J. Tao and Q. Feng: "Compact ultrawideband MIMO antenna with half-slot structure,” IEEE Antennas Wireless Propag. Lett. 16 (2017) 792 (DOI: 10.1109/LAWP.2016.2604344).

[18] J. Deng, et al.: "A dual-band inverted-F MIMO antenna with en- 
hanced isolation for WLAN applications," IEEE Antennas Wireless Propag. Lett. 16 (2017) 2270 (DOI: 10.1109/LAWP.2017.2713986).

[19] L. Wang, et al:: "Compact UWB MIMO antenna with high isolation using fence-type decoupling structure," IEEE Antennas Wireless Propag. Lett. 18 (2019) 1641 (DOI: 10.1109/LAWP.2019.2925857).

[20] X. Liu, et al.: "Wideband MIMO antenna with enhanced isolation for wireless communication application," IEICE Electron. Express 15 (2018) 20180948 (DOI: 10.1587/elex.15.20180948).

[21] X. He, et al.: "MIMO antenna with working-frequency-accompanied isolation characteristic," IEICE Electron. Express 16 (2017) 20170602 (DOI: 10.1587/elex.14.20170602).

[22] A. Ramachandran, et al.: "A compact triband quad-element MIMO antenna using SRR ring for high isolation," IEEE Antennas Wireless Propag. Lett. 16 (2017) 1409 (DOI: 10.1109/LAWP.2016.2640305).

[23] J.-F. Li, et al.: "Compact dual band-notched UWB MIMO antenna with high isolation," IEEE Trans. Antennas Propag. 61 (2017) 4759 (DOI: 10.1109/TAP.2013.2267653).

[24] R. Chandel, et al.: "Tapered fed compact UWB MIMO-diversity antenna with dual band-notched characteristics," IEEE Trans. Antennas Propag. 66 (2018) 1677 (DOI: 10.1109/TAP.2018.2803134).

[25] A.K. Gautam, et al.: "Design of ultra-compact UWB antenna with band-notched characteristics for MIMO applications," Microw. Antennas Propag. 12 (2018) 1895 (DOI: 10.1049/iet-map.2018.0012).

[26] P. Gao, et al.: "Compact printed UWB diversity slot antenna with 5.5GHz band-notched characteristics," IEEE Antennas Wireless Propag. Lett. 13 (2014) 376 (DOI: 10.1109/LAWP.2014.2305772).

[27] A. Toktas: "G-shaped band-notched ultra-wideband MIMO antenna system for mobile terminals," Microw. Antennas Propag. 11 (2017) 718 (DOI: 10.1049/iet-map.2016.0820).

[28] L. Liu, et al.: "Compact MIMO antenna for portable UWB applications with band-notched characteristic," IEEE Trans. Antennas Propag. 63 (2015) 1917 (DOI: 10.1109/TAP.2015.2406892).

[29] Y. Xu, et al.: "Design of a notched-band vivaldi antenna with high selectivity," IEEE Antennas Wireless Propag. Lett. 17 (2018) 62 (DOI: 10.1109/LAWP.2017.2773707).

[30] M. Amin, et al.: "A bowtie-shaped MIMO dielectric resonator antenna for WLAN applications," IEICE Electron. Express 14 (2017) 20170519 (DOI: 10.1587/elex.14.20170519) 